This is the pre-peer reviewed version of the following article: Singh, J., Olsen, E., Vorst, K. and Tripp, K. (2009), RFID tag readability issues

with palletized loads of consumer goods. Packaging Technology and Science, 22: 431-441. doi: 10.1002/pts.864, which has been published in the final form at http://onlinelibrary.wiley.com/doi/10.1002/pts.864/abstract

\title{
RFID Tag Readability Issues with Palletized Loads of Consumer Goods
}

\author{
By J. Singh, E. Olsen, K. Vorst and K. Tripp
}

Department of Industrial Technology, College of Business, California Polytechnic State University, San Luis Obispo, CA

Radio Frequency Identification (RFID) is an automatic identification technology, relying on storing and remotely retrieving data using devices called RFID tags. This technology is being used in enterprise supply chain management-related applications to improve the efficiency of inventory tracking and management. However, this technology has not been able to realize its promised potential because of several factors, such as lack of congruous worldwide standards, privacy issues and less than perfect read rates in supply chain applications. This research aimed to evaluate the readability issues commonly faced by tagged cases of palletized consumer products. The variables studied in this research were productpackage type, tag type, tag location on cases, pallet pattern and forklift speed through a RFID portal representative of a dock door in a warehouse. To determine which variables were the most significant, a binary logistic regression was run. The number of tags read was inputted for the number of events and total number of products per pallet as the number of trials. The variables product content, pallet pattern, and speed, and all interactions were then included in the model. It was observed that readability greatly varies for different product-package systems, with paper towels producing near-perfect reads, followed by bottled water and carbonated soda cans. The slower the forklift truck speed, the better the readability across the board, and the best pallet patterns were dependent on the product-package type. For bottled water, the best pallet pattern was column, and for carbonated soda, the interlocking pattern.

KEY WORDS: RFID; consumer goods; pallet pattern; forklift speed; readability; warehouse

\section{INTRODUCTION}

Radio Frequency Identification (RFID) is a method of identifying items using radio waves. Typically, a reader communicates with a tag that holds digital information on a microchip. ${ }^{1}$ In a business context, RFID is a technology for tracking goods and assets

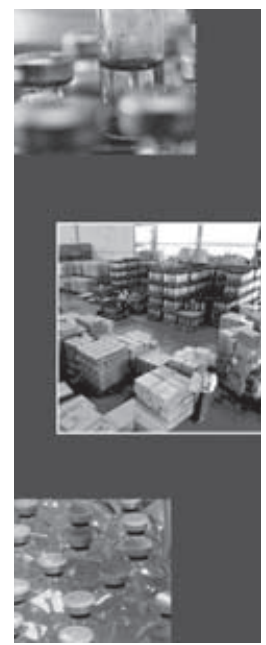


Department of Defense shift their focus to only reading the pallet tag rather than the individual cases on a given pallet, and on reading the case tags only when the pallet is broken down and the cases are put on a conveyor. ${ }^{2}$ These organizations are subscribing to 'singulation' - a method by which an RFID reader identifies a tag with a specific serial number from a number of tags in its field. ${ }^{3}$ Large companies such as Wal-Mart, Albertson's, Best Buy and Target are testing RFID technology to understand its benefits across the supply chain, and Wal-Mart in particular is one of the retailers most aggressively implementing RFID. ${ }^{4}$

Wal-Mart has set the bar high for its suppliers. RFID tags, or labels, on pallets of products have to be read 100 percent of the time as they are driven through a dock door at $8 \mathrm{mph}(13 \mathrm{kph}$ ). Tags on cases also have to be read with perfect accuracy after the pallets are broken down and the cases are put on conveyors moving at speeds of up to 540 feet per minute ( 165 meters per minute). If a company has dozens of different products, each with its own special characteristics, ensuring compliance can be quite a challenge. ${ }^{5}$

Although the supply chain applications are benefiting from consistent improvements in RFID technology, several key issues still remain unresolved. Key amongst these is a lack of reliable and accurate read rates observed during the major logistics operations. The authors note that the standards developed for implementing RFID as a data acquisition technology took less than 100\% readability into account (which is why Electronic Product Code (EPC) codes have special bits to identify the scale of tagged items); nevertheless, they firmly believe that $100 \%$ readability is necessary to achieve the full potential of the system.

Several past studies by the authors of this research have evaluated readability issues in relation to the logistic processes commonly observed in the supply chain. The effect of conveyor belt speeds on readability of tagged cases of consumer products was observed in a recent paper. ${ }^{6}$ Conveyor belt speeds of 200, 400 and $600 \mathrm{ft}$ per min (61, 122 and $183 \mathrm{~m}$ per min, respectively) were used in this study to analyse the readability of tagged cases of paper towels, bottled water and carbonated beverage cans. The study concluded that besides the paper towel cases, the conveyor belt speed had a considerable effect on the read rates of tagged cases. Another study evaluated the effect of moving palletized loads of the same tagged consumer product cases through a warehouse portal at speeds of 1,5 and $10 \mathrm{mph}(1.6,8.1$ and $16.1 \mathrm{kph}$, respectively). ${ }^{7}$ It was observed that fork truck operating speeds had very little effect on read rates. Speeds over $9.3 \mathrm{mph}$ (15 kph) reduced tag read rates by about $10 \%$, as compared to slower speeds around $1.2 \mathrm{mph}(2 \mathrm{kph})$. None of the past studies, including both of these researches, evaluate the effect of varying pallet patterns of readability of tagged cases.

This research, third in the series mentioned above, evaluated the major issues involved in tagging consumer products at the case level for palletization purpose. The purpose of this research was to analyse specific variables that may affect the read accuracy of multiple RFID tags on a pallet when driving a pallet through an RFID portal. The factors considered were product-package type, tag type, tag location on cases, pallet pattern and speed of palletized load through an RFID portal.

\section{MATERIALS AND METHODS}

\section{Product-package systems}

Radio frequency (RF) waves cannot penetrate and reflect off of metals, making it difficult to read tags placed on their surface. Water and other liquids absorb RF waves, which greatly reduces the read range. ${ }^{5}$ The package content can interfere with the RF by reflecting or absorbing these waves as they travel from the tag to the reader. Highly dielectric materials (liquids) and conductors (metal), even in small amounts, can drastically change the properties of a tag antenna, reducing efficiency and shortening the read distance, sometimes to the point of becoming completely unreadable at any distance. ${ }^{2}$ Environmental conditions and materials near RFID systems can affect RF field parameters like reflectivity/refractivity, and absorptive and dielectric properties (detuning). The effect on the RF field based on different materials is shown in Table 1.

This research evaluated the effects of productpackage systems in conjunction with the specific variables of tag placement, pallet pattern and speed of forklift. Many products contain metal and/or 


\section{Table I. The effect on the RF field based on materials ${ }^{8}$}

Material

Effect on RF field

Cardboard

Conductive liquids

Plastics

Metals

Groups of cans

Human body/animals
Absorption (moisture), detuning (dielectric)

Absorption

Detuning (dielectric)

Reflection

Complex effects (lenses, filters), reflection

Absorption, detuning (dielectric), reflection

\section{Table 2. Description of product}

\begin{tabular}{|c|c|c|c|}
\hline Product & Product/case & Case dimensions $(\mathrm{cm})$ & Packaging \\
\hline $\begin{array}{l}\text { Kirkland Signature brand } \\
\text { paper towel rolls }\end{array}$ & $12-27.94 \times 35.56 \mathrm{~cm}$ & $55.88 \times 40.64 \times 27.94$ & $\begin{array}{l}\text { Plastic film used to wrap } \\
\text { individual rolls as well as } \\
\text { the case }\end{array}$ \\
\hline $\begin{array}{l}\text { Kirkland Signature brand } \\
\text { drinking water bottles }\end{array}$ & $35-1 / 2 \mathrm{~L}$ & $46.99 \times 33.02 \times 20.32$ & $\begin{array}{l}\text { Shrink wrapped } \\
\text { corrugated board tray }\end{array}$ \\
\hline Pepsi (regular) cans & I5-237 mL & $33.02 \times 20.32 \times 8.89$ & Paperboard carton \\
\hline
\end{tabular}

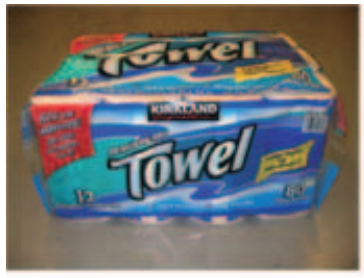

Paper Towel

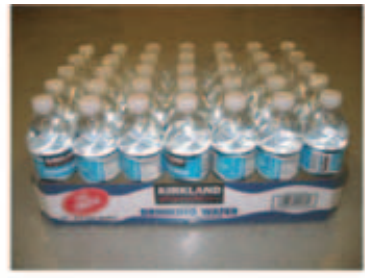

Bottled Water

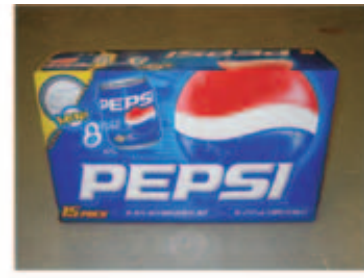

Carbonated Beverage

Figure I. Cases of Product-Package Systems.

water, such as canned foods and drinks. The absorption/reflection property of water and metal can cause a major problem for accurate read rates of an entire pallet. This research investigates whether these problems can be significantly reduced with the right combination of tag placement, pallet pattern and speed of forklift. Figure 1 and Table 2 detail the three product-package systems used in this study.

\section{Pallet patterns}

Cases of packaged product can be loaded on a pallet either in a column, interlocking or pin-wheel pattern, amongst several others. The pattern is primarily chosen to accommodate as many cases as possible for each tier. An interlocking design adds stability as compared to column stacking. Stability is the ability of a package or pallet load to retain 


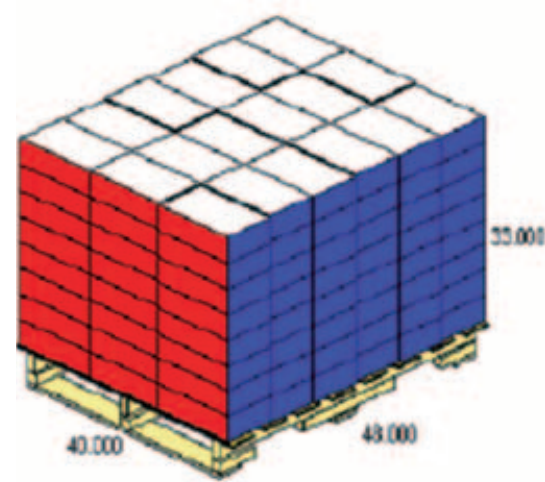

Column

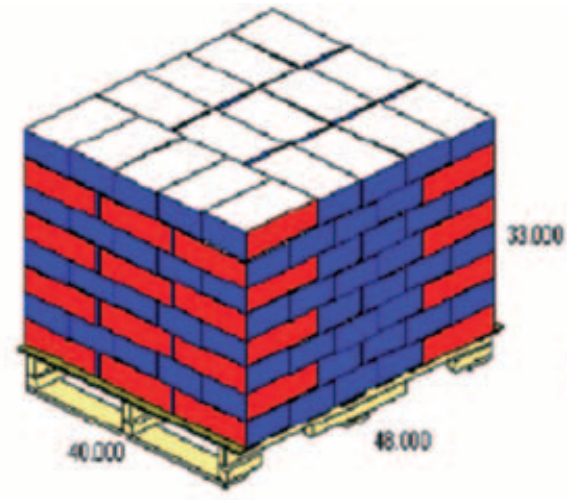

Interlocking

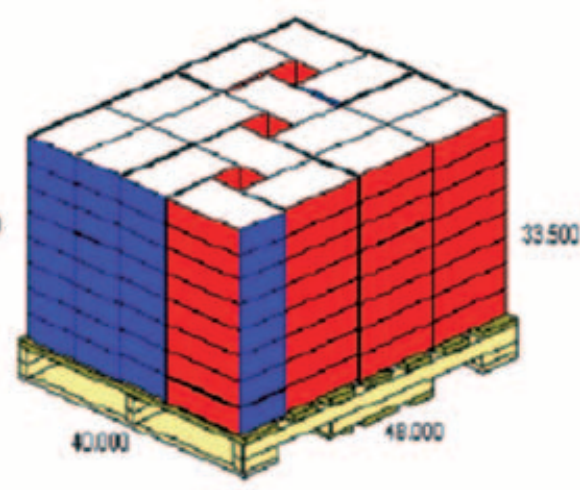

Pinwheel

Figure 2. Pallet Patterns for Carbonated Beverage Cases.

its original quality after prolonged storage. This is because in an interlocking design, movement of a row or column is restricted by an adjacent row or column. Because a higher level of stability is required in the supply chain, interlocking patterns are typically used.

The true benefits of RFID technology may be realized if all individually tagged cases on a pallet can be accurately and repeatedly read. This has been consistently unachievable when a large number of tagged objects are grouped together. A past study was showed only $25 \%$ of the tags on a pallet load of water-filled bottles could be read. ${ }^{9}$ This study, however, did not test different pallet patterns. In order to achieve the maximum read rate, this study used CAPE ${ }^{\circledR}$ palletizing software (South Plainfield, NJ, USA) to create three pallet patterns (column, interlocking and pinwheel) for each product-package system for $40 \times 48$ in pallets $(1.02 \times 1.22 \mathrm{~m}$; Figure 2$)$. The maximum heights of the palletized loads were restricted to those presently used by the respective vendors. These patterns were then tested to discover if pallet pattern had a significant impact on read rate for each test product. No past study has evaluated the effect of pallet patterns on readability of tagged cases.

The number of cases per unitized load for the three product-package types used in this study was different because of the pallet patterns. As can be seen in Figure 2 for beverage cans, the column (144 cases) and interlock patterns (136 cases) have higher numbers of cases as compared to the pinwheel pattern (128 cases). For paper towel and bottled water, the column pallet pattern consisted of 24 and 30 cases respectively, the interlocking pattern consisted of 22 and 35 cases, respectively, and the pinwheel pattern had 18 and 36 cases, respectively, of the two products.

\section{Forklift speed}

One key benefit of RFID over traditional barcode is that RFID tags can be read travelling at greater speeds than barcode labels can. Wal-Mart has mandated that tagged cases on pallets should be readable when carried on a forklift at $8 \mathrm{mph}$ through a portal or dock door. ${ }^{5}$ A study was performed at the University of Florida to look at the relationship between read rate and the speed of the pallet as it moved through a portal. The study found that the faster the pallet moved, the lower the read rate got, which ranged from $90 \%$ at $1 \mathrm{mph}(1.62 \mathrm{kph})$ to $79 \%$ at $4 \mathrm{mph}(6.44 \mathrm{kph}) .{ }^{10}$ Since it is already known that there is a significant relationship between read rate and speed of forklift, this research tests this known relationship and its interaction with the variables of tag placement, package content and pallet pattern. The speeds that were chosen were 1,5 and $10 \mathrm{mph}(1.62,8.05$ and $16.09 \mathrm{kph}$, respectively). These speeds were chosen to simulate the minimum, maximum and average speeds of a 
forklift when unloading pallets in the supply chain.

\section{RFID tag performance}

The importance of the relative orientation of a tag's antenna and those of the interrogator is disputed. Most manufacturers claim that the tag orientation has a diminutive effect on read range and tag readability. An experimental study by Alien Technologies, a leading RFID systems supplier, tested readability under different conditions, including location of tagged cases, antenna type and position, tag orientation, proximity of the tag to the reader, relative orientation of the antenna, number of tags in the field, movement speed through portal, product variables and interference. ${ }^{11}$ The results were encouraging, with a very high percentage $(90-100 \%)$ of tags read regardless of the variables. It was concluded that tag and case orientation had little effect on readability. Liquid and metal products had some effect when tags faced away from the antenna, but 'could be worked around'. However, there are limitations to the findings of these studies. The study does not state the number of tests performed for each variable, and no statistical analysis is reported. Another study concludes that the tag's size, read distance and orientation with the interrogator all effect performance. $^{2}$

Three different Class 1, Gen 2 RFID tags were considered to determine each tag's effect on readability at the case level based solely on productpackage type. The tag that produced the best readability was then chosen for each of the productpackage type. These tags were then used to perform the experiments on the variables of interest for each product. The tags evaluated were of similar size and length, measuring approximately $4 \times 0.5$ in $(10.16 \times 1.27 \mathrm{~cm})$. The three tags used are shown in Figure 3:

- RaflatacG2ShortDipole(UPMRaflatac, Fletcher, NC, USA)

- Avery AD-222 (Avery Dennison RFID, Clinton, SC, USA)

- Alien 'Higgs' (Alien Technology Corporation, Morgan Hill, CA, USA)

Alien Technology Corporation's (Morgan Hill, CA, USA) ALR 9780 RFID reader and ALR-9610 circular polarized antennae were used for this study. Alien Gateway V2.15.08 middleware was used to collect all data. All tests were performed at $0 \%$ attenuation of the reader. Four ALR-9610 circular polarized antennae were used, since they are less sensitive to the tag orientation and sufficed the read distance requirements for this project.

A software, Instant EPC HotSpot software (Integral RFID, Richland, WA, USA) to evaluate the optimum RF performance in terms of the best RFID tag, its orientation and placement location on cases of the three product-package systems was used for this study. ${ }^{12}$ The software was used for this research to conduct an in-depth analysis at every $2.54 \mathrm{~cm}$ (1 in) of the three product-package combinations. Easy-to-comprehend visual results were created to instantly identify the best location for tag placement and tag orientation on cases of each of the three products studied as done for past studies. ${ }^{6,7}$

A map of each case (product-package system) was created. These maps determine the ideal RFID tag for each product as well the optimum location and orientation for an RFID tag across a face of a case. The results for bottled water are shown in
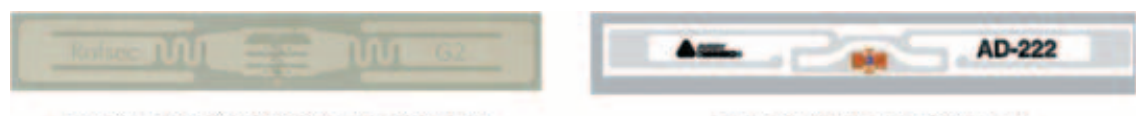

Tag \#1 - Raflatac G2 Short Dipole Inlay

Tag \#2 - Avery AD-222 Inlay

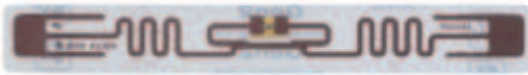

Tag \#3 - Alien "Higgs" Inlay

Figure 3. RFID Tags used for Study. 


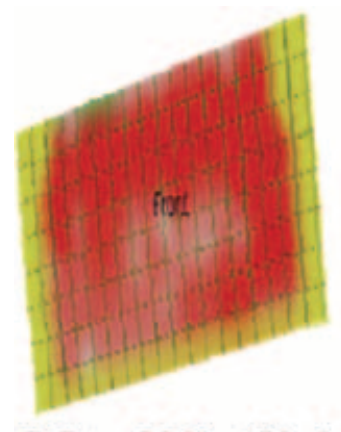

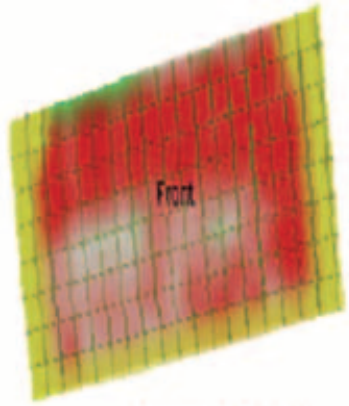

Avery AD-222

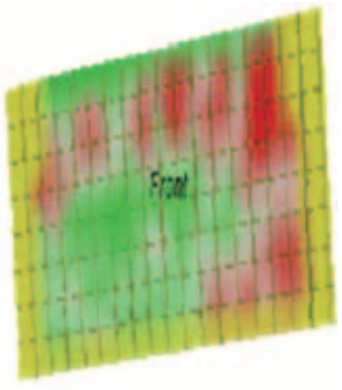

Alien "Higgs"

Figure 4. RF Performance Comparison of Tags Placed Horizontally on Bottled Water Cases.

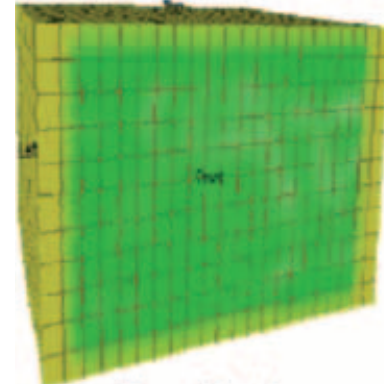

Paper Towels

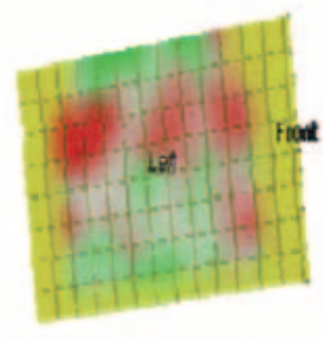

Bottled Water

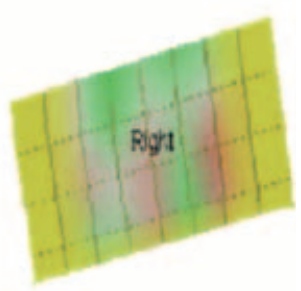

Carbonated Beverage

Figure 5. RF Performance Comparison of Alien Higgs Tags.

Figure 4. The green signifies areas with multiple reads rates of $60-100 \%$, the brighter the colour green, the higher the percentage of reads. White signifies areas with reads rates around 50\% and red signifies locations with reads rates of $40 \%$ and lower; the darker the colour red, the lower percentage of reads.

The Alien Higgs tags in the horizontal position were selected for all three product-package systems because of the more consistent read rates and the practicality of application in association with the size of the cases. Read rates were observed to be $70-80 \%$ for the Alien 'Higgs' tag, while that for the Raflatac G2 Short Dipole, as well as the Avery AD222 , were observed to be no higher then $60 \%$. The average overall read rates for the latter two tags was approximately $30 \%$. The results of the Alien 'Higgs' tag for paper towels, water bottles and canned sodas are shown in Figure 5.

The side face of the products were chosen to be tagged for bottled water and canned soda, rather than the front, because the sides of these products on a pallet had the most direct exposure to the reader antennas on the warehouse portal. ${ }^{6,7}$ For the paper towels, the front face of the product was tagged for the same reason. In a typical supply chain operation, tags are placed mechanically on the cases. This requires a flat and smooth location on the cases in order for the tags to attach easily. The optimal tag location identified for the cases of bottled water was not ideal for a mechanical label applicator as the cases tapered and provided an angled surface for the tags at this location. Hence, the final tag location for the bottled water was on the bottom left of the side face of the case. The final tag location for the paper towels was top left of the front face of the product and that for the canned soda was on top left of the side of the product. Figure 6 shows the final tag locations for all three cases.

Once the RFID tags, tag location and case locations were selected, the EPC HotSpot software was 


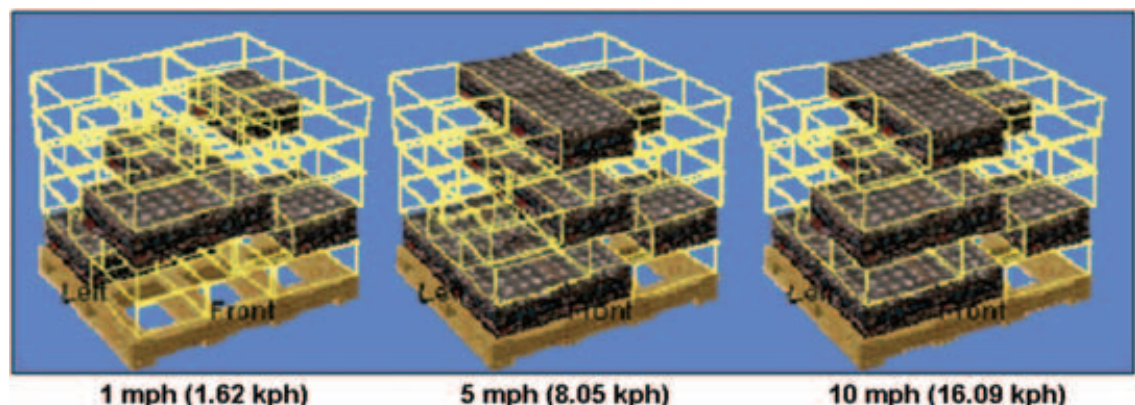

Figure 6. Palletized (Interlocked) Cases of Bottled Water Unread at Different Speeds.

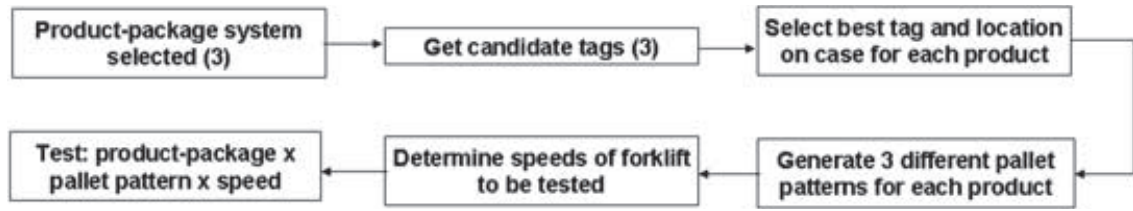

Figure 7. Experimental Design.

configured to identify the location of each case on a pallet. To do this, each case received a tag programmed with a specific number, and each tagged case was placed at a specific location on the pallet. After EPC HotSpot was configured for the pallets, each unitized load was passed through the warehouse portal at the speeds selected. Each pallet load was tested at three speeds with a total of five passes, and a numeric average was recorded for each pass. This was then completed for all three pallet patterns for the three product-package types. As the pallet passed through the portal, EPC HotSpot identified each accurate tag read (three or more reads) with a specific pallet location. Any tags not read were displayed and noted (Figure 6).

Figure 7 shows the overall experimental design used for this study.

\section{RESULTS AND DISCUSSION}

Of the three product-package types selected, paper towels wrapped in plastic film were selected to be the control. Past studies ${ }^{6,7}$ have proven that this product-package system was transparent to RF waves and produced near 100\% reads through warehouse portals when unitized and in the conveyer belt environment as individual cases. Carbonated beverages in aluminium cans and drinking water in plastic bottles, because of their reflective and absorptive properties, respectively, as related to $\mathrm{RF}$, were selected as experimental productpackage systems. Tables 3 and 4 reflect the results of tagged cases of bottled water and beverage cans, respectively, being read when passed through a warehouse portal at the three speeds selected, as well as the three pallet patterns configured for each product-package type. Five passes at three speeds for each pallet pattern and for each productpackage system through the portal were conducted. All values are expressed in the tables as the percentage of the number of cases successfully read out of the total number of cases on each pallet. The reads for palletized paper towels were 100\% for all speeds and pallet patterns used.

The cases of bottled water had higher read rates then expected. According to a previous study, ${ }^{9}$ a read rate of $25 \%$ was expected. The highest read 
Table 3. Results for bottled water

Total number of cases read per pass (\% of total cases)

\begin{tabular}{|c|c|c|c|c|c|c|}
\hline Speed (kph) & 1 & 2 & 3 & 4 & 5 & Average \\
\hline \multicolumn{7}{|c|}{ Column pallet pattern } \\
\hline 1.62 & 100.0 & 96.7 & 100.0 & 100.0 & 100.0 & 99.3 \\
\hline 8.05 & 93.3 & 93.3 & 93.3 & 93.3 & 96.7 & 94.0 \\
\hline 16.09 & 93.3 & 90.0 & 86.7 & 93.3 & 90.0 & 90.7 \\
\hline \multicolumn{7}{|c|}{ Interlocking pallet pattern } \\
\hline 1.62 & 74.3 & 74.3 & 68.6 & 77.1 & 74.3 & 73.7 \\
\hline 8.05 & 68.6 & 62.9 & 71.4 & 68.6 & 62.9 & 66.9 \\
\hline 16.09 & 65.7 & 68.6 & 65.7 & 68.6 & 60.0 & 65.7 \\
\hline \multicolumn{7}{|c|}{ Pinwheel pallet pattern } \\
\hline 1.62 & 61.1 & 61.1 & 61.1 & 61.1 & 61.1 & 61.1 \\
\hline 8.05 & 61.1 & 61.1 & 58.3 & 58.3 & 58.3 & 59.4 \\
\hline 16.09 & 58.3 & 58.3 & 55.6 & 58.3 & 58.3 & 57.8 \\
\hline
\end{tabular}

Table 4. Results for carbonated beverage cans

Total number of cases read per pass (\% of total cases)

\begin{tabular}{|c|c|c|c|c|c|c|}
\hline Speed (kph) & I & 2 & 3 & 4 & 5 & Average \\
\hline \multicolumn{7}{|c|}{ Column pallet pattern } \\
\hline 1.62 & 27.8 & 20.1 & 24.3 & 25.7 & 28.5 & 25.3 \\
\hline 8.05 & 11.8 & 13.2 & 17.4 & 16.0 & 19.4 & 15.6 \\
\hline 16.09 & 12.5 & 10.4 & 14.6 & 13.9 & 12.5 & 12.8 \\
\hline \multicolumn{7}{|c|}{ Interlocking pallet pattern } \\
\hline 1.62 & 46.3 & 45.6 & 44.9 & 44.1 & 44.9 & 45.1 \\
\hline 8.05 & 22.1 & 27.9 & 26.5 & 25.0 & 25.7 & 25.3 \\
\hline 16.09 & 18.4 & 26.5 & 20.6 & 27.9 & 26.5 & 24.0 \\
\hline \multicolumn{7}{|c|}{ Pinwheel pallet pattern } \\
\hline 1.62 & 45.3 & 44.5 & 40.6 & 44.5 & 40.6 & 43.1 \\
\hline 8.05 & 28.1 & 28.1 & 26.6 & 21.1 & 31.3 & 27.0 \\
\hline 16.09 & 21.1 & 22.7 & 28.9 & 26.6 & 25.0 & 24.8 \\
\hline
\end{tabular}

rates were observed for the column-stacked pallet pattern with $99 \%$ at $1 \mathrm{mph}(1.62 \mathrm{kph})$, followed by $94 \%$ at $5 \mathrm{mph}(8.05 \mathrm{kph})$ and $91 \%$ at $10 \mathrm{mph}$ $(16.09 \mathrm{kph})$. For the interlocking and pinwheel pallet patterns, the read rates ranged between $58 \%$ to $74 \%$.

As can be observed from Table 4, the read rates were quite low for the carbonated beverage product-package systems for all three pallet patterns as compared to the two other systems. The interlocking and pinwheel pallet patterns were more readable than the column pattern. On average, the interlocking pallet pattern showed the highest read percentage out of the three patterns. This was $45 \%$ at $1 \mathrm{mph}(1.62 \mathrm{kph}), 25 \%$ at $5 \mathrm{mph}$ (8.05 kph) and $24 \%$ at $10 \mathrm{mph}(16.09 \mathrm{kph})$. The lowest read percentages were from the column pallet pattern. They were $25 \%$ at $1 \mathrm{mph}(1.62 \mathrm{kph})$, $16 \%$ at $5 \mathrm{mph}(8.05 \mathrm{kph})$ and $13 \%$ at $10 \mathrm{mph}$ (16.09 kph). 
Table 5. Binary logistic regression: reads, pallet versus product, pattern, speed (Minitab I5)

Link function: logit

$\begin{array}{lccc}\text { Response information } & \text { Variable } & \text { Value } & \text { Count } \\ & \text { Reads } & \text { Event } & 2745 \\ & & \text { Non-event } & 4890 \\ & & \text { Total } & 7635\end{array}$

Logistic regression table

\begin{tabular}{|c|c|c|c|c|c|c|c|}
\hline \multirow[b]{2}{*}{ Predictor } & \multirow[b]{2}{*}{ Coef } & \multirow[b]{2}{*}{ SE coef } & \multirow[b]{2}{*}{ Z } & \multirow[b]{2}{*}{$P$} & \multirow[b]{2}{*}{ Odds ratio } & \\
\hline & & & & & & Lower & Upper \\
\hline $\begin{array}{l}\text { Constant } \\
\text { Product }\end{array}$ & -1.054 & 0.092 & -11.48 & 0 & & & \\
\hline Water & 5.258 & 0.551 & 9.55 & 0 & 192.05 & 65.25 & 565.28 \\
\hline Pattern & & & & & & & \\
\hline Interlocking & 0.827 & 0.122 & 6.76 & 0 & 2.29 & 1.8 & 2.91 \\
\hline Pinwheel & 0.760 & 0.124 & 6.13 & 0 & 2.14 & 1.68 & 2.73 \\
\hline Speed & -0.096 & 0.016 & -5.98 & 0 & 0.91 & 0.88 & 0.94 \\
\hline Product $*$ pattern & & & & & & & \\
\hline Water $*$ interlocking & -4.024 & 0.582 & -6.91 & 0 & 0.02 & 0.01 & 0.06 \\
\hline Water * pinwheel & -4.499 & 0.578 & -7.78 & 0 & 0.01 & 0 & 0.03 \\
\hline Water & -0.108 & 0.067 & -1.6 & 0.111 & 0.9 & 0.79 & 1.02 \\
\hline Pattern * speed & & & & & & & \\
\hline Interlocking & -0.013 & 0.021 & -0.61 & $0.54 I$ & 0.99 & 0.95 & 1.03 \\
\hline Pinwheel & 0.003 & 0.021 & 0.12 & 0.902 & I & 0.96 & 1.04 \\
\hline Product $*$ pattern $*$ speed & & & & & & & \\
\hline Water $*$ interlocking & 0.176 & 0.073 & 2.4 & 0.016 & 1.19 & 1.03 & 1.38 \\
\hline Water $*$ pinwheel & 0.185 & 0.073 & 2.55 & 0.011 & 1.2 & 1.04 & 1.39 \\
\hline Log-likelihood $=-4185.440$ & & & & & & & \\
\hline Cest that all slopes are zero & 02 & II; & 0 & & & & \\
\hline
\end{tabular}

$95 \% \mathrm{Cl}$

The data in Tables 3 and 4 were analysed using binary logistic regression. The results of the analysis are shown in Table 5. The predicted read probability values are shown in Table 6 and depicted graphically in Figure 8. Paper towels were left out of the analysis because there was no variation in the response variable (read rate was 100\%). The analysis was performed with all main effects of product-package type, pallet pattern and speed included in the model along with all two and threeway interactions. Variables were considered significant with $p<0.05$. The analysis showed that all the main effects were significant, with productpackage type having the greatest effect. RFID tags on cases of water bottles were much more likely to be read than those on beverage can cases. With respect to speed, for tags moving at $10 \mathrm{mph}$ $(16.09 \mathrm{kph})$ there was typically a 0.1 reduction in read probability compared to $1 \mathrm{mph}(1.62 \mathrm{kph})$.
Table 6. Read probabilities predicted by binary logistic regression

Predicted read probability in percent

\begin{tabular}{lcc}
\hline Speed $(\mathrm{kph})$ & $\begin{array}{c}\text { Bottled } \\
\text { water }\end{array}$ & $\begin{array}{c}\text { Aluminium } \\
\text { can }\end{array}$ \\
\hline $\begin{array}{l}\text { Column pallet pattern } \\
\text { I.62 }\end{array}$ & 98.2 & 24.1 \\
8.05 & 96.0 & 17.8 \\
I6.09 & 89.8 & 11.8 \\
Interlocking pallet pattern & & \\
I.62 & 72.4 & 41.7 \\
8.05 & 69.1 & 31.7 \\
I6.09 & 64.7 & 21.2 \\
Pinwheel pallet pattern & & \\
I.62 & 61.0 & 40.4 \\
8.05 & 59.6 & 31.9 \\
I6.09 & 57.7 & 22.7 \\
& & \\
\hline
\end{tabular}




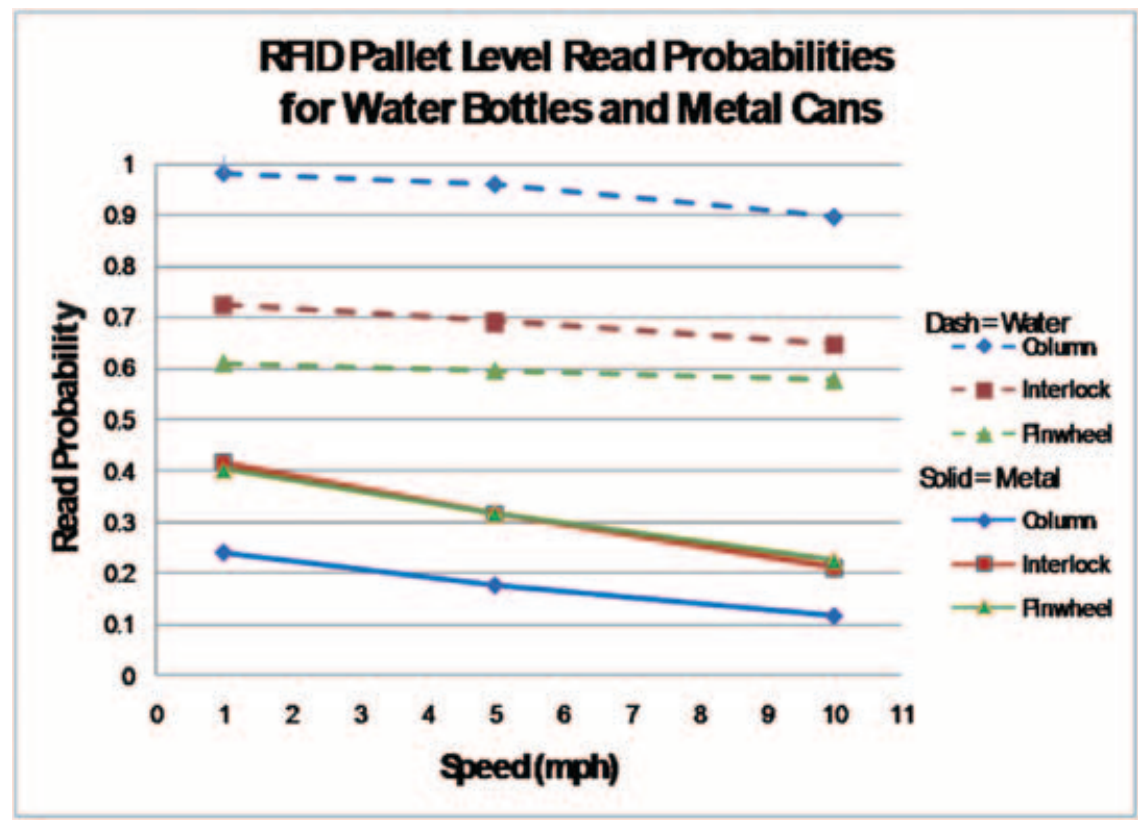

Figure 8. Probability of Tagged Cases Being Read through the Warehouse Portal.

With respect to pallet patterns, tags on the interlocking and pinwheel patterns performed similarly for metal cans and uniformly worse for the column pattern. Conversely, for water bottles, the column pattern performed much better than the interlock and pinwheel patterns. This is indicative of a significant two-way interaction between product and pallet pattern.

There was no significant two-way interaction between product and speed or between pallet pattern and speed. However, a three-way interaction of product-pallet-speed was found to be significant. This can be interpreted as the affect on read rate varying with product, pallet pattern and speed. Figure 8 plots the change in read probability for the various situations that were encountered.

\section{CONCLUSIONS}

Three product-package systems were used to determine if product-package type, tag location, tag type, pallet pattern and speed through a portal have a significant effect on read rate for case level tagging. The results show that all of these variables do have a significant effect.

- The best product-package system in terms of achieving $100 \%$ reliability was paper towels. This is because of paper's known transparency to RF signal. Carbonated beverage products in aluminium cans exhibited the greatest difficulty when trying to achieve a $100 \%$ read rate. This is because of the reflection properties of metal.

- The best location of RFID tags is based on the product-package that is being tagged. This location can be found through software programs such as EPC HotSpot designed by Integral RFID. Out of the three tags tested, the tag that provided the highest probability of reads for all product-package systems tested was the Alien 'Higgs'.

- As reported in several past studies, the lowest speed used to move the palletized load through a portal increased the probability of reading the tags applied to the cases.

- The selection of the optimum pallet pattern depends on the type of product-package. For bottled water, the best type of pallet pattern was 
the column. For the carbonated beverage cans, the best type of pallet pattern observed was the interlocking pattern, followed by the pinwheel pattern.

- Reducing the number of cases in a palletized load does not always guarantee a more efficient read rate. It was demonstrated that fewer cases provided better readability of case level tags for bottled water, but not for beverage cans.

The factors used in this study need to be considered and experimented with prior to finalizing any specifications for adopting RFID in distribution to yield optimum efficiencies in the supply chain.

\section{REFERENCES}

1. RFID Journal. Glossary of terms. 2008; http:/ /www. rfidjournal.com/article/glossary/ [accessed 10 August 2008].

2. Deavours D. RFID journal. Are item-level tags up to the job?. 2007; http://www.rfidjournal.com/ article/articleview/2136/1/128/ [accessed 8 August 2008].

3. King P. RFID journal. Six sigma and the single tag. 2006; http://www.rfidjournal.com/article/ articleview/2102/1/82/ [accessed 10 August 2008].
4. Supply Insight Inc., White Paper. Retail Mandate for RFID. 20 April 2006.

5. RFID Journal. How to get RFID compliant. 2005; http:/ /www.rfidjournal.com/article/ articleview/1046/1/430/ [accessed 20 August 2008].

6. Singh J, Deupser C, Olsen E, Singh SP. An examination of the variables affecting RFID tag readability in a conveyor belt environment. Journal of Applied Packaging Research 2007; 2(2): 61-73.

7. Singh J, Holtz R, Singh SP, Saha K. Effect of unitization and product types on readability of tagged packages of consumer goods. Journal of Applied Packaging Research 2008; 2(3): 189-199.

8. Bukkapatnam S. Sensor (RFID) networks and complex manufacturing systems monitoring (Commsens): laboratory for RFID research. Unpublished Research, Oklahoma State University, Stillwater, Oklahoma, 2005.

9. Clarke R, Twede D, Tazelar J, Boyer K. Radio frequency identification (RFID) performance: the effect of tag orientation and package content. Packaging Technology and Science 2006; 19(1): 45-54.

10. Collins J. RFID journal. University takes a fresh approach to RFID. 2005; http://www.rfidjournal. com/article/articleview/1742/1/4/ [accessed 25 August 2008].

11. Alien Technologies. RFID supply chain applications building test 1 (pp. 2-19). 2002; A White Paper, Alien Technologies, Morgan Hill, CA

12. Integral RFID, instant EPC HotSpot user guide, software version: 2.5, 2007 